\title{
PELA ORGANIZAÇÃO DA ESCOLA E DO ENSINO: O SELF-GOVERNMENT DE ANTÓNIO SÉRGIO
}

DOI: http://dx.doi.org/10.1590/2236-3459/51249

\author{
Maria João de Carvalho \\ Universidade de Trás-os-Montes e Alto Douro, Portugal. \\ José Viegas Brás \\ Universidade Lusófona de Humanidade e Tecnologias, Portugal. \\ Maria Neves Gonçalves \\ Universidade Lusófona, Portugal.
}

\begin{abstract}
Resumo
Compreender a educação passa, inevitavelmente, por pensarmos todos aqueles que contribuíram para a renovação das práticas pedagógicas. Conhecer cada um dos protagonistas é compreender toda a educação a partir dos obstáculos que cada um teve que ultrapassar. Com este artigo pretendemos compreender o contributo da obra de António Sérgio para a renovação da educação na primeira metade do século 20 em Portugal. Como fontes utilizámos conferências, cartas, textos doutrinários e ensaios. Os descritores que utilizámos na análise foram crítica à pedagogia tradicional, pedagogia qualitativa, self-government e a escola-município, ensino infantil e primário. Em conclusão, o autor foi um forte opositor ao ensino tradicional e impulsionador de uma educaçao baseada no self-government.

Palavras-chave: António Sérgio, self-government, pedagogia, renovação do ensino.
\end{abstract}

\section{FOR ORGANISING THE SCHOOL AND TEACHING: THE SELF-GOVERNMENT OF ANTÓNIO SÉRGIO}

\section{Abstract}

Understanding the education passes inevitably think about all those who have contributed to the renewal of teaching practices. Meet each of the protagonists is to understand the entire education

\begin{tabular}{|l|l|l|l|l|l|l|}
\hline Hist. Educ. [Online] & Porto Alegre & v. 19 & n. 46 & Maio/ago., 2015 & p. 131-144
\end{tabular}


from the obstacles that each had to overcome. With this article we want to understand the contribution of António Sérgio for renewal of education in the first half of the 20th century in Portugal. We used as sources conferences, letters, doctrinal texts and essays. The descriptors that we used in the analysis were critique of traditional pedagogy, qualitative pedagogy, selfgovernment and school-municipality, infantile and primary education. In conclusion, the author was a strong opponent to the traditional teaching and great booster of an education based on selfgovernment.

Key-words: António Sérgio, self-government, pedagogy, renewal of teaching.

\title{
PARA LA ORGANIZACIÓN DE LA ESCUELA Y LA FORMACIÓN PROFESIONAL: EI SELF-GOVERNMENT DE ANTÓNIO SÉRGIO
}

\begin{abstract}
Resumen
Entender la educación pasa inevitablemente pensar en todos aquellos que han contribuido a la renovación de las prácticas pedagógicas. Conocer cada uno de los protagonistas es entender la educación completa teniendo en cuenta los obstáculos que cada uno tenía que superar. Con este artículo queremos entender la contribución de António Sérgio para la renovación de la educación en la primera mitad del siglo 20 en Portugal. Hemos utilizado como fuentes conferencias, cartas, textos doctrinales y ensayos. Los descriptores que hemos utilizado en el análisis fueron crítica de la pedagogía tradicional, pedagogía cualitativa, autogobierno y escuela-municipio, educación infantil y primaria. En conclusión, el autor fue un fuerte opositor a la enseñanza tradicional y gran promotor de una educación basada en la autonomía

Palabras-clave: António Sérgio, self-government, pedagogía, renovación de la enseñanza.
\end{abstract}

\section{POUR L'ORGANISATION DE L'ÉCOLE ET L'ENSEIGNEMENT PROFESSIONNEL: LE SELF-GOVERNMENT DE ANTÓNIO SÉRGIO}

\begin{abstract}
Résumé
Comprendre l'éducation passe inévitablement pour penser à tous ceux qui ont contribué au renouvellement des pratiques pédagogiques. Connaître chacun des protagonistes doit comprendre éducation toute entière à partir des obstacles que chacun a dû surmonter. Avec cet article, nous voulons comprendre la contribution d'António Sérgio pour la rénovation de l'enseignement dans la première moitié du $20^{\mathrm{e}}$ siècle au Portugal. Nous avons utilisé comme sources des conférences, des lettres, des textes doctrinaux et des essais. Les descripteurs que nous avons utilisés dans l'analyse ont été critique de la pédagogie traditionnelle, pédagogie qualitative, autonomie et l'école et la municipalité, éducation infantile et primaire. En conclusion, l'auteur a été un adversaire fort à l'enseignement traditionnel et un grand propulseur d'une éducation basée sur l'autonomie. Mots-clé: António Sérgio, self-government, pédagogie, renouvellement de l'enseignement.
\end{abstract}




\section{Introdução}

om este trabalho pretendemos analisar os contributos de António Sérgio para o pensamento educacional português e reflectir sobre a pertinência das suas preocupações relativamente à pedagogia.

António Sérgio fez parte de uma plêiade de intelectuais republicanos que se empenharam na crítica e na renovação da educação em Portugal. Inserido neste movimento crítico, destacámos a sua participação nas conferências sobre a reforma da educação nacional, promovidas pela Sociedade de Estudos Pedagógicos, da qual faziam parte pedagogos de referência, tais como João de Deus Ramos, João de Barros, Adolfo Lima e outros, onde teve oportunidade de se posicionar face à educação dominante, pela comunicação $O$ ensino como factor de ressurgimnto nacional, defeitos dos nossos métodos de ensino e maneiras de os corrigir - linhas gerais de uma nova organização ${ }^{1}$.

Para responder a este desafio utlizámos diversas fontes primárias, nomeadamente conferências, cartas pessoais e sobre o ensino, textos doutrinários e ensaios diversos. Foi sobre os textos de teor mais pedagógico que incidiu o nosso trabalho analítico e reflexivo na certeza de que falar de educação em António Sérgio é percebermos a atualidade do seu pensamento pelo protagonismo que the confere e por acreditar que é o meio por excelência capaz de uma profunda reforma de mentalidade que tão imperiosamente exige. Uma educação pautada pela emancipação e pela liberdade que bem nos faz lembrar Paulo Freire.

As fontes foram trabalhadas mediante os seguintes descritores: crítica à pedagogia tradicional; pedagogia qualitativa; self-government e a escola-município; organização do ensino Infantil e primário; as vias do ensino pós-primário.

A sua proposta de reforma educativa visa à criação de uma alma nova ${ }^{2}$ e obriga ao protagonismo das ciências não pelos conhecimentos, em nível de conteúdos, que proporcionam, mas antes pela atividade de racionalização a que os seus métodos obrigam. Neste sentido, é percetível que a tarefa do professor não consiste tanto no fornecer, por intermédio do discurso, os resultados conhecidos, mas auxiliar, provocar o interesse, apresentar problemas que o aluno deverá procurar solucionar.

António Sérgio (1883-1969) é, sem dúvida, um dos intelectuais que merece uma reflexão sobre a sua vida e o legado da sua obra. Foram já diversos autores como Hameline e Nóvoa (1990), Nóvoa (1994), Fernandes (1972, 1978, 1979, 2008), Ricardo (2011), Matos (1983), Pires (1989) e Ventura $(1988,1994)$, que se debruçaram sobre este notável pensador e pedagogo português. Contudo revisitar a obra de Antonio Sérgio suscita sempre novos olhares e novas abordagens.

António Sérgio nasceu em Damão, então uma colónia portuguesa. Viveu dos três até perto dos dez anos no Congo português de que seu pai era governador. A sua educação, sensivelmente até aos dez anos foi marcada pela sua condição social. Com dez anos chegou a Portugal, frequentou uma escola para se preparar para o exame de instrução primária e poder ingressar no Colégio Militar. Depois de terminar o Colégio Militar e o curso de oficias da Armada e da Escola Naval foi para o Oriente. Com a implantação da República deixou a Armada:

\footnotetext{
${ }^{1}$ Sobre esta conferência, consulte-se Ricardo (2011, p. 113-120).

2 Sobre a concepção da alma nova na I República, consulte-se Brás; Gonçalves (2011, p. 21-44). 
Abandonei a Armada quando se instaurou a República, no empenho de manter a minha liberdade crítica e de me dedicar à vocação que me parecia a minha: ensinar o povo a governar-se a si mesmo, graças a métodos de educação modernos e a novas praxes sócio-económicas [...]. Decidira consagrar-me ao meu próprio rumo (o do apostolado cívico) et me tenir ferme dans les courants. (Sérgio, 1957, p. 25)

Dedicou-se à indústria cultural, à actividade literária e editorial e à docência ${ }^{3}$. Quer na leccionação, quer na sua vasta obra, projectam-se os alicerces dos princípios da Escola Nova e de métodos activos.

\section{Crítica à pedagogia tradicional}

Contrariamente à educação tradicional, estática, silenciosa, recetiva da exposição e do monólogo magistral, que crê que as grandes obras são universalmente comunicáveis, valorizando, desta feita, o saber livresco e enciclopédico que utiliza uma metodologia verbal e dogmática, a Educação Nova pauta-se por apresentar um conhecimento relativo e construído. Motivo que justifica que a aprendizagem seja percebida como um processo natural e espontâneo que brota do interior do educando.

Por isso, neste contexto, a educação não é algo que se apresenta à criança, mas antes o desenvolvimento natural dos seus dons e interesses, o que resulta num papel ativo e interativo por parte do educando, consequência da mutação do papel do mestre transformando a motivação numa atitude pessoal alicerçada ao interesse.

Esta é uma escola formadora e simultaneamente democrática que favorece a descoberta e a emergência de valores. É uma escola assente no primado da Psicologia que mobiliza a atividade produtiva da criança utilizando a energia que dela parte, que concretiza o seu processo educativo alicerçado no interesse, na resposta às necessidades do desenvolvimento da criança que, ao reivindicar a individualização, reconhece o direito à individualidade própria de cada criança. É uma escola de ligação à vida; reconhece o trabalho manual como um importante fator na preparação para a vida, anulando a instrução passiva e formal, facto que é sintomático do grande interesse pela socialização e é uma educação pela liberdade que se traduz na necessidade de deixar a criança viver libertando-a de qualquer imposição que venha do exterior, fazendo uso da criatividade própria de cada educando.

Sérgio (1939) posiciona-se, claramente, em oposição ao ensino tradicional que considerava como sofrendo de alguns vícios que o tornavam inócuo e mesmo perigoso. Este tipo de ensino era marcado, sobretudo, por um caráter abstrato, verbalista, descritivo e mnemónico. O caráter abstrato revela-se, essencialmente, no facto de esta escola se encontrar, em termos de conteúdos, completamente desajustada, dir-se-ia mesmo, separada da realidade vivida pelo aluno. Na verdade, "a sobrevalorização da memória e a mecânica repetição a que os conteúdos ficam sujeitos aniquila qualquer possibilidade de criação, de transformação, diríamos mesmo de uma hipotética oportunidade do educando intervir no mundo" (Carvalho, 2009, p. 44).

${ }^{3}$ Sobre a vida de António Sérgio, consulte-se Fernandes (2008, p. 13-28). 
Os métodos utilizados acentuavam, sobretudo, o caráter verbalista, em que o manejo da realidade é substituído pelo das palavras, nas quais se encerra, onde, perante as possibilidades de fazer a experiência ou descrevê-la, o professor opta muito mais pela descrição em vez de colocar o aluno perante a possibilidade real de a desenvolver [à experiência].

Por fim, o caráter mnemónico, incentivado por este tipo de pedagogia, merece reparos, pois o entendimento de Sérgio é o de que o trabalho do educador não se reduz à mera transmissão da informação, pressupondo o aluno como sendo uma tábua rasa que, gradualmente, se vai preenchendo de conhecimentos. Aí, a sua autonomia, o desenvolvimento do espírito crítico, não encontram um solo propício onde possam desenvolver-se, antes pelo contrário. Diríamos que a escola "ao não propiciar atitudes de reflexão, de problematização e de participação não pode ser entendida como um espaço de debate, de discussão e, concomitantemente, de "conscientização"” (Carvalho, 2009, p. 44). No fundo, trata-se do confronto entre uma pedagogia da quantidade por oposição a uma pedagogia da qualidade.

O que se confronta também são os conceitos de educar e instruir que, com alguma frequência, são confundidos, mas que na realidade não têm o mesmo âmbito de aplicação. Confundi-los só se pode transformar em algo funesto, pois na redução da educação à instrução e desta a um simples processo de alfabetização está, para Sérgio, a principal causa das várias tentativas fracassadas de ressurgimento nacional levadas a cabo pelos republicanos desde meados do século 19. A educação como instrução, meio utilizado para ensinar o povo a ser povo, não possibilita o alcance do objetivo proposto.

Esta escola é classificada por Sérgio como uma verdadeira calamidade pública (1918), ideia que o autor acentua quando diz que "educar uma criança enviando-a à actual escola é como preparar um automobilista metendo-o no museu dos coches reais" (1980a, p. 117).

Para obviar a tudo isto o autor propõe uma pedagogia muito próxima da Escola Nova, cuja estruturação deve ter no seu horizonte o preceito kantiano de que "não se deve educar para a sociedade de hoje, mas para uma sociedade melhor, possível no futuro" (1977, p. 188).

\section{Em defesa de uma pedagogia qualitativa}

O espírito desta escola carateriza-se, fundamentalmente, por colocar no primeiro plano da atividade educativa o educando em detrimento do educador.

O educando passa a ser alvo de um detalhado estudo com o objetivo de abordar todas as dimensões que me si encerra, o que, como consequência, nos leva ao conhecimento de todas as necessidades que se querem satisfeitas por si próprias, embora sejam constatados pelo educador a partir de objetos e estratégias por si pensadas, de modo a que possa desenvolver, o mais convenientemente possível, todas a as suas capacidades.

É, em suma, uma escola na vida, formando o cidadão ativo e útil para a sociedade que se quer democrática. E, por isso, não é estranho que ao aluno lhe seja outorgado um papel ativo, assumindo-se como ator e não como um mero executante. O professor oferece muito mais a explicação do que a discrição visando desenvolver, sobretudo, processos que promovam a inteligência do educando e não competências mnemónicas.

\begin{tabular}{|l|l|l|l|l|l|}
\hline Hist. Educ. [Online] & Porto Alegre & v. 19 & n. 46 & Maio/ago., 2015 & p. 131-144 \\
\hline
\end{tabular}


A educação estará, então, na base da formação personalidade do próprio educando, será uma atividade libertadora das suas próprias potencialidades, em que o respeito pela individualidade, pois cada um é segundo as suas aptidões, tem lugar neste processo educativo.

À escola de súbditos contrapõe Sérgio uma escola criadora de homens autónomos, livres, o cidadão empenhado e ativo.

Por isso, a reforma educativa proposta por Sérgio pretende alcançar não só a dimensão escolar, mas, também a social, a económica e a cultural. Trata-se, por isso, de uma revolução pedagógica de âmbito global.

Para que tal desiderato se concretize são as ciências a desempenhar a principal função, não pelos conhecimentos, em nível de conteúdos, que proporciona, mas antes pela atividade de racionalização a que os seus métodos obrigam: o método da descoberta, por um lado, pelo uso da análise ou indução, que vai "das consequências para os princípios, dos fenómenos para as suas leis" (Sérgio, 1939, p. 71) e, por outro, pelo método expositivo, pelo uso da síntese ou dedução que parte "dos princípios [...] para os factos observáveis" (Sérgio, 1939, p. 71).

Foi o próprio Sérgio quem elaborou o modelo de uma lição ideal, cujo objetivo primeiro seria o desenvolvimento do espirito crítico:

Colocar os alunos perante um problema e mostrar os factos que se relacionam com ele, convidá-los a que imaginassem experiências que verificassem ou condensassem essas hipóteses, selecionasse com eles a hipótese verdadeira (por experimentação), assistisse ao encadeamento das ideias obtidas, e levá-los a discutir em comum o enunciado das ideias a que chegaram. (1993, p. 94)

Daqui decorre a importância que Sérgio atribui ao método, isto é, a uma pedagogia de método em oposição a uma pedagogia de conteúdo. Ainda que não se possa menosprezar os programas e a organização do ensino, estes são secundários por comparação com a importância dos métodos. Sérgio chega a defender não se revestir de particular importância, pois o que importa no ensino "é ter pedagogos de pedagogia prática, não é ter cientistas, é ter professores que senhoreiem a técnica, os modernos processos da sua arte" (1939, p. 19).

Na sua ótica, a escola deve "ensinar pouca coisa, mas afundo" (1939, p. 12), deve promover a atividade de racionalização, de iniciativa intelectual em oposição ao desenvolvimento da memória. Fica claro que o autor desvaloriza a transmissão de conteúdos em favor do método, do caminho escolhido para aprender a aprender. Esta conceção encontra a discordância de alguns autores, nomeadamente em Patrício, quando diz "que Sérgio privilegia enormemente - e a nosso ver erradamente - o método em relação ao conteúdo no processo educativo" (1984, p. 41).

O professor tem a responsabilidade de, recorrendo ao ensinamento socrático, conduzir os alunos metodicamente no acesso à luz pela observação do real. Neste sentido, é percetível que a tarefa do professor não reside tanto no fornecer, por intermédio do discurso os resultados conhecidos, mas antes auxiliar, conduzir, provocar o interesse, apresentar problemas que o aluno deverá procurar solucionar (Sérgio, 1916). 
Assim, mais do que fornecer um resultado acabado, ao professor cabe estimular a curiosidade do educando de modo a que este se venha a converter em atividade intelectual, suportada por uma autonomia e competência crítica na busca do resultado.

\section{O self-government e a escola-município}

Ao contrário de alguns autores que, em nome de certo nacionalismo, recusam qualquer tipo de importação, Sérgio defende exatamente o contrário e chega mesmo a afirmar que "o grande erro foi não importar suficientemente" (1915, p. 27), propondo uma educação assente no "desenvolvimento da iniciativa, da vontade criadora, da responsabilidade, do auto-domínio, do self-government” (1915, p. 3).

Não é, pois, uma fidelidade de vassalo (Sérgio, 1980b, p. 145) que a escola deve promover, mas sim "uma disciplina de carácter" (Sérgio, 1915, p. 32) que desenvolva a autonomia nos educandos. Ou seja, que os torne homens com iniciativa, que se saibam fazer valer, que contém consigo em detrimento do chefe e possam contar sempre com eles próprios e não com o Estado, bem como a criação da mentalidade do cidadão consciente, com vontade criadora, responsabilidade e autodomínio (Sérgio, 1914a).

O sucesso do self-government não depende de fatores externos, como, por exemplo, a raça, a nacionalidade, a idade ou género, como atestam os exemplos de Cuba e dos Estados Unidos, mas sim da forma como o professor o aplica, abolindo a coerção, coisa que a criança despreza, e o antagonismo entre mestre e discípulo. O professor ter uma atitude dirigente e discreta atribuirá responsabilidade ao educando, o que como consequência, permitirá uma maior valorização da autonomia que se lhe dá, existindo entre ambos uma relação de profunda colaboração.

Emancipar o educando é o escopo essencial da sua pedagogia que exige ação. Só pela ação se produz atividade, pois nenhum processo de instrução, nem os inúmeros discursos proferidos constantemente pelos mestres, nem mesmo a poesia jamais incitaram o educando a atuar, nem o levaram a participar em atos com os quais no futuro se há-de confrontar.

Importante é que tenhamos uma educação que conceba um bom cidadão no hábito da ação municipal, colocando-o em condições idênticas às que encontrará na idade adulta (Sérgio, 1914b). Esta nova educação que se deve fazer sentir nas nossas escolas deveria levar à consciência das

necessidades fundamentais da sã existência social; teria de reproduzir o condicionamento económico e postulados de ordem ética de uma justa e fecunda sociedade adulta, justa, ponderada mas também tonificante, porque Ihe cabia disciplina mas ao mesmo tempo impulsionar [...] a expansão do indivíduo (Sérgio, 1914c, p. 120)

Se existir uma educação que passe do enciclopedismo para a criação teremos como resultado um aluno com espírito de iniciativa produtora que será, posteriormente, motivo de progresso para a sociedade (Sérgio, 1914d). A forma do self-government escolar que Sérgio sugeria, por lhe parecer a mais recomendável, que se aplicasse no nosso país, era a do município.

Seria um erro se considerássemos o conceito de Educação Cívica como sinónimo de educação ou formação política, pois se assim fosse teríamos que considerar como o 
melhor cidadão, aquele que possuísse o maior número possível de conhecimentos políticos. A Educação Cívica é, antes de mais, um veículo ao serviço do educando que lhe permitirá a formação de uma mentalidade, ou melhor, de um caráter que em si mesmo encerra as verdadeiras virtudes cívicas, a saber, responsabilidade, autonomia, respeito e valor moral.

Daqui se depreende que fortalecer o caráter do educando é o intuito primordial desta educação, para que seja possível impulsionar o interesse pela comunidade a que pertencem, para se colocarem ao serviço de uma atitude consciente e voluntária, tendo como suporte a eficiência moral.

O conhecimento dos deveres e dos direitos do cidadão é, também, uma das premissas na qual assenta a Educação Cívica. Preparar o cidadão era, para Sérgio, um objetivo fundamental, vendo na Educação cívica, "no estudo e no governo de si mesmo e da comunidade escolar a que pertence" (Patrício, 1984, p. 42) o meio mais próprio para ascender e exercitar a liberdade. Ora, a criação de hábitos úteis para a vida em sociedade não se adquirem se essa mesma realidade se encontra ausente, se as relações sociais que se dão na realidade não estiverem presentes, será o mesmo que querer ensinar os meninos a nadar fazendo com que pratiquem os movimentos próprios fora de água, nunca Ihes possibilitando a experiência vivida (Kerschensteiner, s.d.).

Assim sendo, exige-se que a escola seja um microcosmo do Estado atribuindo aos alunos um conjunto de tarefas representativas da realidade social, onde terão uma participação pessoal, responsável na vida da comunidade escolar e no trabalho conjunto dentro do grupo.

Também Dewey tem, como um dos aspetos mais aliciantes do pensamento, a defesa da ideia de que a educação é vida ou um processo de vida, mais do que preparação para a vida, o que obriga a uma escola ao serviço da sociedade, em que seja notória a correspondência entre a natureza teórica dos programas escolares e as vivências concretas dos alunos. Põe uma ênfase acentuada no conceito de experiência pela importância que este adquire no processo de aprendizagem, que define como uma reconstrução contínua do conhecimento.

O conhecimento, na sua ótica, diferencia-se do mero acumular de informação instrução -, encontra, isso sim, identificação com o saber utilizar informação. Desta feita, a educação deve ser entendida como um processo social de comparticipação da experiência, em que a existência de uma correspondência efetiva entre a natureza teórica dos programas escolares e as vivências concretas dos alunos seja uma constante.

Esta pedagogia desenvolve-se segundo a ideia de que só se aprende o que se pratica, cujas situações sejam tão reais quanto as de fora da escola, e não por uma ambiente que se caraterize por situações que o educando, possivelmente, nunca venha a viver, residindo o valor do conhecimento nos efeitos práticos que dele decorrem pragmatismo. A escola deve reger-se por uma linha democrática, que sirva a democracia.

Também a educação cívica se faz decididamente, pela ação, pela prática, e para que a escola dê resposta a esta condição ela terá que se transformar num verdadeiro município. O município escolar é o meio encontrado por Sérgio para a concretização da liberdade do educando no governo de si próprio e da comunidade escolar que integra, estratégia a que não é alheia a ideia de que a escola deve ser a reprodução da vida social dos homens adultos. 
Dar possibilidade aos jovens de vivenciarem as verdadeiras condições da experiência social e, assim, desenvolver em cada um o espírito de cidadania, ao mesmo tempo "que se propõe desenvolver o altruísmo e [...] criar reformadores" (Kerschensteiner, s.d., p. 42), é algo que Ihes será propiciado pela escola-município. Desta forma se libertam da passividade em que vivem imersos e que a escola atual alimenta e reproduz. Será a ação da educação cívica que transformará a escola num verdadeiro município, organizado como um corpo político independente, com os seus órgãos legislativo, executivo e judicial com leis próprias. Com efeito, "a participação dos atores nas diferentes tomadas de decisão na organização escolar é um dos aspetos que mais evidencia a sua configuração democrática" (Carvalho, 2012, p. 119).

Estudantes eleitos manterão a ordem, promoverão a camaradagem e a amizade entre todos, julgarão as faltas dos discípulos através de tribunais por si constituídos, libertando os professores dessa função (Sérgio, 1960).

O governo da comunidade da escola será a reprodução em miniatura da sociedade real. Serão os estudantes a governarem-se a si próprios, embora com a indispensável "assistência, conselho e a cooperação discreta dos professores" (Kerschensteiner, s.d., p. 36).

É no município escolar que o jovem começará a exercer a sua conduta cívica tendo como suporte, como método escolar para fomentar esta aprendizagem, o selfgovernment, conceito que não nos é dado por quem nos governa, mas que depende da incansável busca no quotidiano de quem é governado, que aprende pela prática e não por qualquer ensino (Sérgio, 1917). É um exercício que deve ser feito "não só no ambiente escolar, pelas actividades profissionais e pela instituição do self-government, [...] mas também na sociedade exterior" (Sérgio, 1917, p. 23).

Será a aplicação, na escola organizada em comunidade, do self-government que será subsidiário da possibilidade de emancipar a juventude, os próprios educandos. Diríamos, e numa aproximação a Sérgio,

que a organização escolar é, em si mesma, insuficiente para transformar a sociedade mas também não podemos deixar de considerar o grande contributo que pode dar nesse sentido, através da implementação e do exercício de práticas democráticas no seu interior. (Carvalho, 1012, p106)

\section{A organização do ensino infantil e primário}

É ao ensino infantil, dos 3 aos 7 anos, ainda não criado, que Sérgio dedicou grande interesse, ao mesmo tempo que preconizava a reorganização da escola primária.

No que respeita ao ensino infantil, propunha que se adotasse o método de Maria Montessori assente na espontaneidade que "deriva misteriosamente da vida interior da criança - por muito tempo reprimida pela contínua intervenção dos adultos" (Montessori, s.d., p. 7), que será apontada como ideia diretriz a nortear toda a ação dos pedagogos, não perdendo do horizonte que a criança é um ser ativo, criador que jamais deve ser reprimido, devendo a escola tudo fazer para respeitar a sua natureza. Esta autora concebe a educação, ou melhor, o processo educativo em torno do princípio de autoeducação, fundado sobre a liberdade da criança no respeitante à sua atividade que se quer ordenada e fiscalizada por ela mesma, sendo que qualquer manifestação levada a cabo, em que se reconheça utilidade, deverá ser reprimida. Todo o trabalho 
desenvolvido deve alicerçar-se na alegria e voluntarismo, reconhecido por Montessori como o aflorar da verdadeira disciplina.

O self-control é um conceito profundamente implantado em toda esta teoria educativa, pois em qualquer exercício praticado pela criança está inerente o cultivo do poder motor da vontade.

Os instrumentos didáticos e os meios propostos por Sérgio, para além do que é sugerido pela pedagoga italiana, têm também em vista a prática da jardinagem, a criação de animais, a horticultura e mesmo o trabalho topográfico, na medida em que este contribuiria para o aperfeiçoamento da ortografia. Não é esquecido o papel relevante que podem desempenhar na educação infantil as histórias e o jogo, este último pelo papel lúdico que lhe está inerente, servindo de motivação á leitura e à literatura.

Para que a educação infantil não seja um exercício inútil é necessário obedecer a alguns princípios, considerados por Sérgio, como essenciais. Deve, pois, considerar-se a verdadeira natureza da criança, sendo que o seu crescimento físico e mental é autónomo, não devendo o educador interferir de maneira inoportuna e destrutiva, mas intervindo no seu ambiente, afastando os obstáculos que impossibilitem esse fluxo natural de crescimento. Deixar a criança ser criança torna-se palavra de ordem.

Esta liberdade que se quer para a criança não é sinónimo de abandono ou negligência, ao invés disso devemos ter uma atitude prudente e, simultaneamente, afetuosa (Montessori, 1966).

A escola primária, e mais particularmente a escola primária rural, é igualmente uma das preocupações fundamentais de Sérgio que pretende dar resposta à necessidade de integrar a "escola o mais possível na vida económica e social da aldeia e servindo-lhe directamente as necessidades fundamentais" (Fernandes, 1979, p. 75). Desta feita, o estudo deverá "ganhar feição regionalista, integrar-se nas actividades económicas locais" (Sérgio, 1916, p. 58), ou seja, cada escola ao desenvolver determinada atividade o faça de acordo com a natureza da região. O estudo da História e da Geografia irão possibilitar a intervenção da criança, mais tarde, nos problemas da sociedade. A Botânica, a Zoologia e a Aritmética têm como aliadas as atividades concretas que a elas se ligam. A interdisciplinaridade e a experiência, bem como o desenvolvimento da iniciativa mental e a atividade espontânea do aluno encontram espaço no seu projeto pedagógico para o ensino primário.

Por este motivo, as atividades escolares serão múltiplas, indo da agricultura à pesca, da fiação à tecelagem. É um ensino que se pauta por ser universal e que põe em evidência o desenvolvimento da aprendizagem do educando. A educação profissional não é descurada no projeto pedagógico do autor, pois já a incluí na instrução primária como propedêutica á frequência da escola técnica.

\section{As vias do ensino pós-primário}

Após a escola primária, que terminava aos 12 anos, Sérgio propunha uma ramificação no ensino onde distinguia duas vias tendo em conta as suas finalidades. Uma delas conduzia os alunos à universidade, opção que implicava a frequência no ensino secundário e universitário, a segunda via era destinada àqueles jovens que não seguiam o ensino superior, e denominou-a de ensino primário superior ou de continuação. 
Fernandes (1979) considera que Sérgio ignorava que o ensino de continuação mantinha um caráter socialmente discriminatório, sobretudo numa sociedade em que se verificavam antagonismos de classe. Ideia que Sérgio contraria quando aponta como objetivos da escola do futuro "anulação progressiva dos antagonismos sociais, e a instauração da sociedade justa, pela escola Única do Trabalho" (Fernandes, 1928, p. 8).

O ensino primário e de continuação, que duraria até aos 18 anos, combinaria uma formação geral, mas menos sólida e aprofundada do que aquela que era oferecida pelos liceus, e uma formação técnica, visando à preparação para o exercício de uma profissão após o términus do curso. Este tipo de formação tinha em mente a preparação dos jovens técnicos com competências para a ocupação de cargos médios nas hierarquias.

As escolas de continuação, distintas dos liceus, conjugavam o ensino e o desempenho de uma atividade profissional, dando continuidade à ligação estreita entre o trabalho e o ensino propostos para a escola primária. Assim, a par de uma instrução técnica, haveria uma dimensão prática a desenvolver em oficinas, laboratórios e granjas escolares acompanhada de profissionais especializados.

É de salientar que embora este ensino acolhesse "jovens sem dotes mentais bastantes para triunfarem nos estudos universitários" (Sérgio, 1952, p. 257), era suficientemente maleável para possibilitar a transferência dos mesmos, do ensino de continuação para o liceu, caso mostrassem, mesmo tardiamente, o serem especialmente dotados. Igualmente de salientar é a possibilidade que os alunos teriam, uma vez selecionados, de usufruir de bolsas de estudo, quando a situação económica do aluno não fosse satisfatória.

A reforma prevista por Sérgio não esqueceria o ensino normal, o que exigiria uma remodelação nos quadros docentes, agora bem treinados e a fazerem uso de novos métodos. A alteração curricular era um dos pontos a ter em conta atribuindo um especial relevo às disciplinas de âmbito pedagógico e didático, bem como à Língua Inglesa que pretende ver introduzida. Deu preferência aos professores do ensino secundário no recrutamento de docentes para as quatro escolas modelo experimentais que pretendia criar.

\section{Conclusão}

A noção de educação em Sérgio é atravessada pela influência kantiana que impõe como grande meta da ação educativa libertar o homem de todas as formas de tutelas e tutores, facilitando o trânsito da menoridade para a maioridade, outorgando-lhe um papel ativo que não se compraz com a assimilação, instrução ou alfabetização.

Como foi possível verificar, António Sérgio punha-se em oposição ao ensino tradicional que se caraterizava por um carácter abstrato, verbalista e mnemónico, com expressão numa escola assente no "desenvolvimento da iniciativa, da vontade criadora, da responsabilidade, do autodomínio e do self-government" (1915, p. 27) que se compagina com o desenvolvimento da autonomia dos próprios educandos.

O interesse que tinha pelo ensino infantil, pela reorganização do ensino primário e pelo ensino secundário e superior não podem, por isso, ser marginais à importância que Sérgio atribui à organização da escola e do ensino como meios para transformar a sociedade. 
O sistema educativo terá como missão formar o cidadão e prepará-lo para o trabalho produtivo. Profundamente influenciado pelas ideias da Escola Nova, Sérgio acreditva que só a transformação da escola, dos professores e dos alunos poderia abrir caminho à transformação da sociedade, à reforma de mentalidades, em direção a uma sociedade de homens livres, educados na liberdade e para a liberdade. Neste ideário, que tem como quadro de referência, defende que a espontaneidade e dinamismo do educando não poderia deixar de apresentar uma conceção pedagógica que favorecesse a sua liberdade e iniciativa intelectual. Atribui aos educadores um papel de vanguarda e de grande aptidão na utilização dos métodos ativos, ao mesmo tempo em que propunha uma nova organização escolar: o município escolar. Tais aspetos têm sempre no horizonte a meta para que aponta a conceção sergiana de educação: a criação de sujeitos livres, ativos, autónomos, emancipados, participando ativa e solidariamente numa escola-comunidade, regida pelos princípios do self-government.

Para António Sérgio, o sucesso do self-government depende da forma como o professor age na sua prática educativa e terá sempre no horizonte a emancipação por uma pedagogia ativa. A forma do self-government escolar que o autor julgava dever-se aplicar no nosso país era a do município. Assim sendo, exige-se que a escola seja um microcosmo do Estado, atribuindo aos alunos um conjunto de tarefas representativas da realidade social e para que a escola dê resposta a esta condição terá que se transformar num município escolar.

\section{Referências}

BRÁS, José Viegas; GONÇALVES, Maria Neves. O governo da alma pública: finais da Monarquia e $1^{\text {a }}$ República. In: BRÁS, José Viegas; GONÇALVES, Maria Neves. $O$ imperativo republicano em debate. Lisboa: Edições Universitárias Lusófonas, 2011, p. 2144.

CARVALHO, Maria João de. A modalidade de escolha do diretor na escola pública portuguesa. Revista Lusófona de Educação, n. 22, 2012, p. 103-121.

CARVALHO, Maria João de. Paulo Freire: a construção da escola democrática a partir da decisão. Revista Brasileira de Política e Administração da Educação, v. 3, n. 25, 2009, p. 41-54.

CUNHA, Norberto. Conhecimento e história em António Sérgio. Gil Vicente, n. 13-14, 1983, p. 21-28.

FERNANDES, Rogério (Int. e notas). Cartas de António Sérgio a Álvaro Pinto (19111919). Lisboa: Edição da Revista Ocidente, 1972.

FERNANDES, Rogério. Duas cartas inéditas de António Sérgio para Afonso Lopes Vieira. Colóquio/Letras, n. 46, 1978, p. 57-66.

FERNANDES, Rogério. A pedagogia portuguesa contemporânea. Lisboa: Instituto de Cultura Portuguesa, 1979.

FERNANDES, Rogério. António Sérgio: notas biográficas. Revista Lusófona de Educação, n. 12, 2008, p. 13-28.

HAMELINE, Daniel; NÓVOA, António. Autobiografia inédita de António Sérgio: escrita aos 32 anos no Livre d'Or do Instituto Jean-Jacques Rousseau (Genève). Revista Crítica de Ciências Sociais, 1990, p. 141-178. 
KERSCHENSTEINER, Georg. La educación cívica. Barcelona: Labor, s.d.

MARTINS, Moisés de Lemos; PINTO, Manuel (orgs.). Mentalidade democrática e educação na seara nova e na obra de António Sérgio. CONGRESSO DA ASSOCIAÇÃO PORTUGUESA DE CIÊNCIAS DA COMUNICAÇÃO, 5, 2008. Actas ... Braga: Centro de Estudos de Comunicação e Sociedade, 2008, p. 1782-1795.

MATOS, A. Campos. Bibliografia de António Sérgio. Revista de História das Ideias, Coimbra, v. 5, 1983, p. 1025-1107.

MIMOSO, Anabela. O ideário republicano educativo da $1^{a}$ série da revista A Águia. In BRÁS, José Viegas; GONÇALVES, Maria Neves (org.). O imperativo republicano em debate. Lisboa: Edições Universitárias Lusófonas, 2011, p. 101-107.

MONTESSORI. Maria. A criança. Lisboa: Portugália, 1966.

MONTESSORI. Maria. Montessori em família. Lisboa: Portugália, s.d.

NÓVOA, António. António Sérgio. In: UNESCO. Thinkers on education. Unesco: Publishing/Oxford \& IBH Publishing, v. 4, 1994, p. 501-518.

PATRÍCIO, Manuel Ferreira. António Sérgio: figuras da pedagogia contemporânea. Évora: Universidade de Évora, 1984.

PATRÍCIO, Manuel Ferreira. A lógica de António Sérgio. Revista Portuguesa de Filosofia, n. 43, 1987, p. 1-30.

PIRES, Daniel. Prefácio. António Sérgio em Macau: nove cartas inéditas. Revista de Cultura, Macau, 1988-1989, p. 110-156.

RICARDO, Maria Manuel Calvet. As teses de António Sérgio sobre a educação: o ensino como factor de ressurgimento nacional. In: BRÁS, José Viegas; GONÇALVES, Maria Neves. O imperativo republicano em debate. Lisboa: Edições Universitárias Lusófonas, 2011, p. 113-120.

SÉRGIO, António. O self-government e a escola. A Águia, v. V, 1914a, p. 187-189.

SÉRGIO, António. O self-government e a escola I. A Águia, v. VI, 1914b, p. 25-29.

SÉRGIO, António. O self-government e a escola II. A Águia, v. VI, 1914c, p. 58-64.

SÉRGIO, António. O self-government e a escola III. A Águia, v. VI. Porto, 1914d, p. 91-96.

SÉRGIO, António. Educação cívica. Renascença Portuguesa. Porto, 1915.

SÉRGIO, António. Considerações histórico-pedagógicas antepostas a um manual de instrução agrícola na escola primária. Renascença Portuguesa. Porto, 1916.

SÉRGIO, António. Função social dos estudantes e a sua preparação para a intervenção futura na sociedade portuguesa. Renascença Portuguesa. Porto, 1917.

SÉRGIO, António. O ensino como factor de ressurgimento nacional: defeito dos nossos métodos de ensino e maneira de os corrigir: linhas gerais de uma nova organização. Renascença Portuguesa. Porto, 1918.

SÉRGIO, António. Prefácio. Transformemos a escola de A. Ferrière. Paris: Livraria Francesa e Estrangeira, 1928.

SÉRGIO, António. Sobre educação primária e Infantil. Lisboa: Inquérito, 1939.

SÉRGIO, António. Cartas ao terceiro homem. Obras completas. Lisboa: Livraria Sá da Costa, 1952. 
SÉRGIO, António. Cartas do terceiro homem: porta voz das Pedras vivas do País real. Terceira série. Lisboa: Inquérito, 1957.

SÉRGIO, António. Prefácio. Em prol da educação popular. Porto: Marânus, 1960.

SÉRGIO, António. Ensaios I. Obras completas. Lisboa: Livraria Sá da Costa, 1997.

SÉRGIO, António. Ensaios II. Obras completas. Lisboa: Livraria Sá da Costa, 1980a.

SÉRGIO, António. Ensaios III. Obras completas. Lisboa: Livraria Sá da Costa, 1980b.

VENTURA, António. António Sérgio e António Augusto Ferreira de Macedo: marcos de um convívio epistolar (1919-1949). In: VENTURA et al. Estudos sobre António Sérgio. Lisboa: Instituto Nacional de Investigação Científica/Centro de História da Universidade de Lisboa, 1988, p. 51-116.

VENTURA, António. José Régio/António Sérgio: correspondência (1933-1958). Portalegre: Câmara Municipal de Portalegre/Centro de Estudos José Régio, 1994.

MARIA JOÃO DE CARVALHO é professora na Universidade de Trás-os-Montes e Alto Douro e investigadora integrada no Centro de Investigação e Intervenção Educativa da Universidade do Porto.

Endereço: Escola de Ciências Humanas e Sociais/Departamento de Educação e Psicologia - Universidade de Trás-os-Montes e Alto Douro - Quinta de Prados 5001-801 - Vila Real.

E-mail: mjcc@utad.pt.

JOSÉ VIEGAS BRÁS é professor e investigador na Universidade Lusófona de Humanidades e Tecnologias. Doutor em História da Educação pela Faculdade de Psicologia e Ciências da Educação da Universidade de Lisboa. Co-editor da Revista Lusófona de Educação.

Endereço: Instituto de Educação da Universidade Lusófona - Campo Grande, 376 1749-024 - Lisboa - Portugal.

E-mail: zevibras@gmail.com.

MARIA NEVES GONÇALVES é investigadora integrada no Ceied - Universidade Lusófona.

Endereço: Instituto de Educação da Universidade Lusófona - Campo Grande, 376

1749-024 - Lisboa - Portugal.

E-mail: maria.neves.g@gmail.com.

Recebido em 28 de outubro de 2014.

Aceito em 7 de março de 2015. 